\title{
Long-term macrolide treatment for the prevention of acute exacerbations in COPD: a systematic review and meta-analysis
}

This article was published in the following Dove Press journal: International Journal of COPD

\author{
Yanan Cui' \\ Lijuan Luo' \\ Chenbei $\mathrm{Li}^{2}$ \\ Ping Chen' \\ Yan Chen' \\ 'Department of Respiratory Medicine, \\ The Second Xiangya Hospital, \\ Central South University, Changsha, \\ Hunan 4I00II, China; ${ }^{2}$ Biomedical \\ Clinical Medicine, The Queen Marry \\ University of London of Nanchang \\ University, Jiangxi, China
}

Correspondence: Yan Chen

Department of Respiratory Medicine,

The Second Xiangya Hospital, Central

South University, No 139 Renmin Road,

Changsha 410000, China

$\mathrm{Tel}+86$ I3 50847 I738

Email chenyan99727@csu.edu.cn
Background: Acute exacerbation of COPD (AECOPD) is associated with an increased hospitalization and mortality. Azithromycin and erythromycin are the recommended drugs to reduce the risk of exacerbations. However, the most suitable duration of therapy and drug-related adverse events are still a matter of debate. The aim of this meta-analysis was to assess the current evidence regarding the efficacy and safety of long-term macrolide treatment for COPD.

Materials and methods: We comprehensively searched PubMed, Embase, the Cochrane Library, and the Web of Science and performed a systematic review and cumulative metaanalysis of all randomized controlled trials (RCTs) and retrospective studies.

Results: Eleven RCTs and one retrospective study including a total of 2,151 cases were carried out. Long-term macrolide treatment significantly reduced the total number of cases with one or more exacerbations $(\mathrm{OR}=0.40 ; 95 \% \mathrm{CI}=0.24-0.65 ; P<0.01)$ and the rate of exacerbations per patient per year (risk ratio $[\mathrm{RR}]=0.60 ; 95 \% \mathrm{CI}=0.45-0.78 ; P<0.01$ ). Subgroup analyses showed that the minimum duration for drug efficacy for both azithromycin and erythromycin therapy was 6 months. In addition, macrolide therapy could improve the St George Respiratory Questionnaire (SGRQ) total score $(P<0.01)$ but did not achieve the level of clinical significance. The frequency of hospitalizations was not significantly different between the treatment and control groups $(P=0.50)$. Moreover, chronic azithromycin treatment was more likely to increase adverse events $(P<0.01)$.

Conclusion: Prophylactic azithromycin or erythromycin treatment has a significant effect in reducing the frequency of AECOPD in a time-dependent manner. However, long-term macrolide treatment could increase the occurrence of adverse events and macrolide resistance. Future large-scale, well-designed RCTs with extensive follow-up are required to identify patients in whom the benefits outweigh risks.

Keywords: AECOPD, macrolide, azithromycin, adverse events

\section{Introduction}

COPD is a preventable and treatable disease that is characterized by persistent respiratory symptoms and airflow limitation. ${ }^{1}$ The incidence of COPD is gradually increasing. It is estimated that the number of COPD cases is more than 300 million worldwide, with a global prevalence of $11.7 \% .^{2}$ Meanwhile, there are around 3 million deaths annually across the world. ${ }^{2}$ Recently, in China, a large-scale epidemiological investigation shows that the overall prevalence of spirometry-defined COPD was $8.6 \%$, accounting for 99.9 million adults with COPD. ${ }^{3}$ The high morbidity and mortality of COPD is also associated with significant economic and social burden. Acute exacerbations of COPD (AECOPDs) refer to an acute worsening of respiratory symptoms that require 
additional therapy and are usually associated with increased airway inflammation and mucus production and marked gas trapping. ${ }^{1}$ AECOPD is an important event in the management of COPD and a major determinant of health status and prognosis for patients with COPD. Exacerbations also account for the greatest proportion of the total COPD burden on the health care system. ${ }^{1}$ Therefore, prevention of exacerbations is essential for the management of COPD.

Exacerbations are mainly triggered by respiratory viral and bacterial infections although air pollution, smoking, and ambient temperature may also contribute to these events. Currently, there are two main strategies to prevent AECOPDs; these include pharmacological interventions with long-acting bronchodilators, inhaled corticosteroids (ICS), phosphodiesterase-4 inhibitors, and mucoregulators and nonpharmacological interventions such as vaccines, smoking cessation, pulmonary rehabilitation, and lung volume reduction. ${ }^{1}$ However, the effects of these measures are limited, and approximately, one-third of patients with COPD experience one or more exacerbations every year. ${ }^{4}$ Moreover, chronic inflammation plays an important role in the pathogenesis of COPD, which leads to the widespread use of corticosteroids for treatment. However, high-dose corticosteroid inhalation provides little benefit in terms of improving the $\mathrm{FEV}_{1}$ and may have long-term detrimental effects. ${ }^{5}$ Thus, it is important to identify new and effective anti-inflammatory pharmacological therapies for COPD.

In previous studies, the continuous and prophylactic use of antibiotics has not been routinely recommended for COPD patients owing to insufficient evidence in reducing incidence of AECOPDs and concerns about the antibioticrelated side effects and drug resistance. ${ }^{1}$ However, in 2017, the GOLD recommended for the first time that treatment with azithromycin or erythromycin for 1 year in patients prone to exacerbations can reduce the risk of exacerbations compared to usual care. ${ }^{6}$ Macrolides are of unique interest because, in addition to their antibacterial and antiviral effects, they possess anti-inflammatory effect and immunomodulating activity. ${ }^{7,8}$ These properties have been suggested to contribute to reducing disease progression of diffuse pan-bronchiolitis, ${ }^{9}$ cystic fibrosis, ${ }^{10}$ non-cystic fibrosis bronchiectasis,${ }^{11}$ and idiopathic pulmonary fibrosis. ${ }^{12}$ Accordingly, macrolides should be considered as a potential therapy in COPD.

Several randomized controlled trials (RCTs) have been conducted to test this hypothesis with different conclusions. Furthermore, some meta-analyses have also been conducted to evaluate these findings, with the conclusion that prophylactic macrolide therapy is effective in decreasing the frequency of exacerbations in patients with COPD. ${ }^{13-17}$ However, the most suitable drug, drug dose, duration of therapy, and target population remain unclear. ${ }^{18}$ There is also no agreement on the long-term safety related to the emergence of macrolide resistance and adverse events. ${ }^{19}$ Recently, several relevant trials have been newly published, and the revised GOLD 2017 document has also proposed prophylactic macrolide therapy. Therefore, we performed a systematic review and an updated meta-analysis to assess the efficacy and safety of long-term macrolide treatment for the prevention of AECOPDs.

\section{Materials and methods \\ Literature search strategy}

A literature search was performed on May 1, 2018, without restriction to regions, time, and publication types. The primary sources were the Cochrane Library and the electronic databases of PubMed, Embase, and the Web of Science. We used the following search term in the [Title/Abstract]: (COPD OR COAD OR Chronic Obstructive Pulmonary Disease OR Obstructive Pulmonary Disease OR Chronic Obstructive Airway Disease) AND (Azithromycin OR Erythromycin OR Macrolide OR Macrocyclic Lactone) AND (Exacerbation OR AE). We also used the "Related Articles" function to broaden the search and selected relevant articles from the reference lists of all retrieved studies, review articles, and conference abstracts.

\section{Inclusion and exclusion criteria}

To be included in the analysis, a study had to fulfill the following criteria: 1) it was a RCT or retrospective comparative study (cohort or case-control study); 2) it enrolled adults with a diagnosis of stable COPD but not AECOPD; 3 ) the prophylactic use of macrolides must have been administered orally at least one time a week for a period of at least 3 months; and 4) it had at least one of the quantitative outcomes mentioned in the following section of this article. The exclusion criteria included the following: 1) the study included patients with asthma, bronchiectasis, cystic fibrosis, or other genetic diseases; 2) it had a limited data on exacerbations; and 3) the article type was an editorial, letter to the editor, review article, case report, conference abstract, or an animal experimental study.

\section{Data extraction and outcomes of interest}

Data from the included studies were extracted independently by two of the authors (Yanan Cui and Lijuan Luo). Any disagreement was resolved by the adjudicating senior author (Yan Chen), and a final consensus was reached among all 
the authors. We extracted the first author, year of publication, country, study design, sample size, population characteristics, antimicrobial agent, dose administered, duration of the treatment, and information on outcome measures. The primary outcomes were the total number of patients with one or more exacerbations and the rate of exacerbations per patient per year. The secondary outcomes were the number of patients requiring hospitalization, health-related quality of life based on the St George Respiratory Questionnaire (SGRQ) score, and the total number of patients who experienced adverse events.

\section{Quality assessment and statistical analyses}

The methodological quality of RCTs was assessed by the Cochrane risk of bias tool. ${ }^{20}$ The modified Newcastle-Ottawa Scale that consists of patient selection, comparability of study groups, and assessment of outcome was used to assess the methodological quality of retrospective studies. ${ }^{21}$ A score of 0-9 (allocated as stars) was allocated to the relevant study. RCTs including five or more items of low risk of bias and retrospective studies achieving six or more stars were considered to be of high quality.

Pooling analyses of the total number of patients with exacerbations, hospitalizations, and adverse effects were performed with Review Manager 5.3 (Cochrane Collaboration, Oxford, UK), and the OR was used to compare dichotomous variables. Meanwhile, the risk ratios (RRs) for exacerbations per patient per year and the mean differences in change of SGRQ score were pooled with Comprehensive Meta-Analysis V2.2. Further, 95\% CIs were calculated for all clinical end points. Statistical heterogeneity was quantified using the $I^{2}$ statistic. The random-effects model was used if there was a heterogeneity between studies $\left(I^{2}>40 \%\right)$; otherwise, the fixed-effects model was used. ${ }^{20}$ Subgroup analyses were performed to compare different macrolides and macrolide therapy duration. Sensitivity analyses were performed by deleting studies with the highest or lowest weight and were conducted only for high-quality RCTs. Funnel plots were used in the analysis of potential publication bias.

\section{Results}

\section{Literature search}

A total of 626 potentially relevant articles were initially identified ( 80 from PubMed, 170 from Embase, 101 from the Cochrane Library, and 275 from the Web of Science). After screening the titles and abstracts, 346 articles were excluded. Of the remaining 51 articles with full texts, 12 studies including 2,151 cases fulfilled the predefined inclusion criteria and were included for the final analysis (Figure 1). Eleven studies were RCTs, ${ }^{22-32}$ and one report was a retrospective observational study. ${ }^{33}$ Examination of the reference lists of the included studies and the review articles did not yield any further relevant studies for evaluation.

\section{Characteristics of eligible studies}

The characteristics of included studies are shown in Table 1. These studies, published between 2001 and 2018, were mostly conducted in UK. The study population, with ages generally ranging from 65 to 73 years, included more men than women. Most of the patients had moderate-to-severe COPD diagnosed by current spirometric criteria, with mean $\mathrm{FEV}_{1}$ of $33.9 \%-56.5 \%$ of the predicted value. A total of 1,078 patients were allocated to the macrolide treatment group (seven studies for azithromycin, three studies for erythromycin, one study for clarithromycin, and one study for roxithromycin), and 1,023 were allocated to the control group. The duration of macrolide therapy was more than 3 months but less than 1 year. Evaluation suggested that the quality of the enrolled RCTs was ideal (Figure 2), and the retrospective study also received seven stars (Table 2 ).

\section{Primary outcomes}

Eleven studies involving 1,910 cases reported the total number of patients with one or more exacerbations..$^{22-28,30-33}$ In a pooled analysis of the 11 studies, long-term macrolide treatment significantly reduced AECOPDs compared with the control group $(\mathrm{OR}=0.40 ; 95 \% \mathrm{CI}=0.24-0.65 ; P=0.0003$, $I^{2}=62 \%$; Figure 3 ). In the subgroup analyses of the specific macrolide (Figure 4A), AECOPDs were significantly decreased in both the azithromycin-treated group $(\mathrm{OR}=0.48$; $\left.95 \% \mathrm{CI}=0.31-0.76 ; P=0.002, I^{2}=35 \%\right)$ and the erythromycintreated group $(\mathrm{OR}=0.22 ; 95 \% \mathrm{CI}=0.09-0.53 ; P=0.0008$, $I^{2}=53 \%$ ). However, for clarithromycin therapy, only one trial reported the frequency of AECOPD and showed no statistical difference between the treated and control groups. ${ }^{23}$ In addition, macrolide treatment for 3 or 6 months did not improve the exacerbation rate ( $P=0.25$ and 0.15 , respectively), whereas the OR showed a reduction of $72 \%(\mathrm{OR}=0.28 ; 95 \%$ $\mathrm{CI}=0.12-0.68 ; P=0.005, I^{2}=81 \%$ ) among the total number of patients with AECOPDs taking macrolides for 12 months, compared with the controls (Figure 4B).

Nine studies ${ }^{22,23,25-28,30-32}$ including 1,631 patients reported the rate ratios for exacerbations per patient per year. Pooling the data of these studies showed a significant reduction in the rate of exacerbations $(\mathrm{RR}=0.60 ; 95 \% \mathrm{CI}=0.45-0.78 ; P<0.01$, $I^{2}=63.73 \%$ ) following the macrolide treatment (Figure 5). 


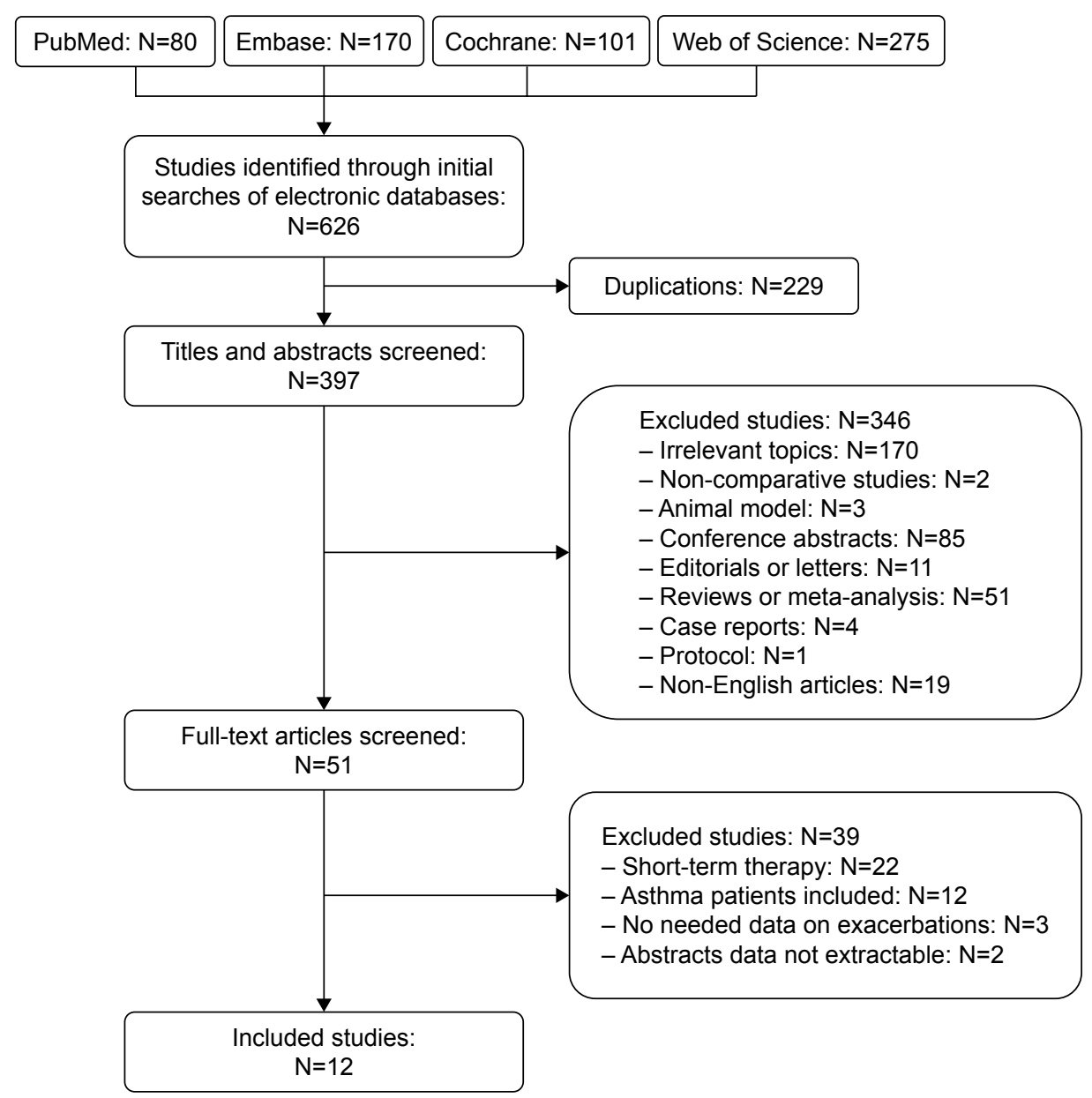

Figure I Flow diagram of studies identified, included, and excluded.

\section{Secondary outcomes}

Pooling the data of four trials ${ }^{24,25,28,31}$ including 324 patients, which reported the number of patients requiring hospitalization, showed that there was no significant difference between the macrolide treatment and control groups $(\mathrm{OR}=0.60$; $95 \% \mathrm{CI}=0.14-2.65 ; P=0.50, I^{2}=69 \%$; Figure 6 ).

As for health-related quality of life, five studies ${ }^{19,21,23,27,29}$ involving 872 patients reported the mean differences in change in total SGRQ score. Macrolide treatment apparently improved the total SGRQ score (mean difference $=-2.47$; 95\% CI=-3.72 to $1.22 ; P<0.01, I^{2}=13.72 \%$; Figure 7 ). Although we found a statistically significant reduction of SGRQ score in the treatment group, the change was not clinically significant ( $\geq 4$-point reduction).

All included studies ${ }^{22-33}$ reported on the total number of patients who experienced nonfatal adverse events during follow-up after treatment with macrolides compared with the control group. Prophylactic macrolide therapy was more likely to increase adverse events $(\mathrm{OR}=1.63 ; 95 \%$ $\mathrm{CI}=1.30-2.04 ; P<0.01, I^{2}=35 \%$; Figure 8 ). In subgroup analyses, there was a tendency for more adverse events in the azithromycin- and roxithromycin-treated groups $\left(\mathrm{OR}=1.51 ; 95 \% \mathrm{CI}=1.17-1.95 ; P=0.002, I^{2}=45 \%\right.$ and $\mathrm{OR}=3.21 ; 95 \% \mathrm{CI}=1.56-6.60 ; P=0.002$, respectively). However, three studies using erythromycin ${ }^{27,28,31}$ and one study using clarithromycin ${ }^{23}$ showed no significant difference between the two groups ( $P=0.60$ and 0.18 , respectively; Figure 9A). Moreover, the pooled data showed that patients treated with macrolides for 3 or 12 months suffered more drug-related adverse events than those in the control groups (both $P<0.05$ ). Moreover, there was no statistical difference between the 6-month treatment subgroup and the control ( $P=0.10$; Figure 9B). Gastrointestinal reactions were the most frequent adverse events in the treatment groups, and hearing decrements were also frequent in such patients.

\section{Sensitivity analyses and publication bias}

After eliminating studies with the highest or lowest weight ${ }^{22,25}$ and a retrospective study, ${ }^{33}$ nine RCTs that included five or more items of low risk of bias using the Cochrane risk of bias tool were included in the sensitivity analyses..$^{23,24,26-32}$ Of note, in subgroup analyses of the 6-month therapy including only 


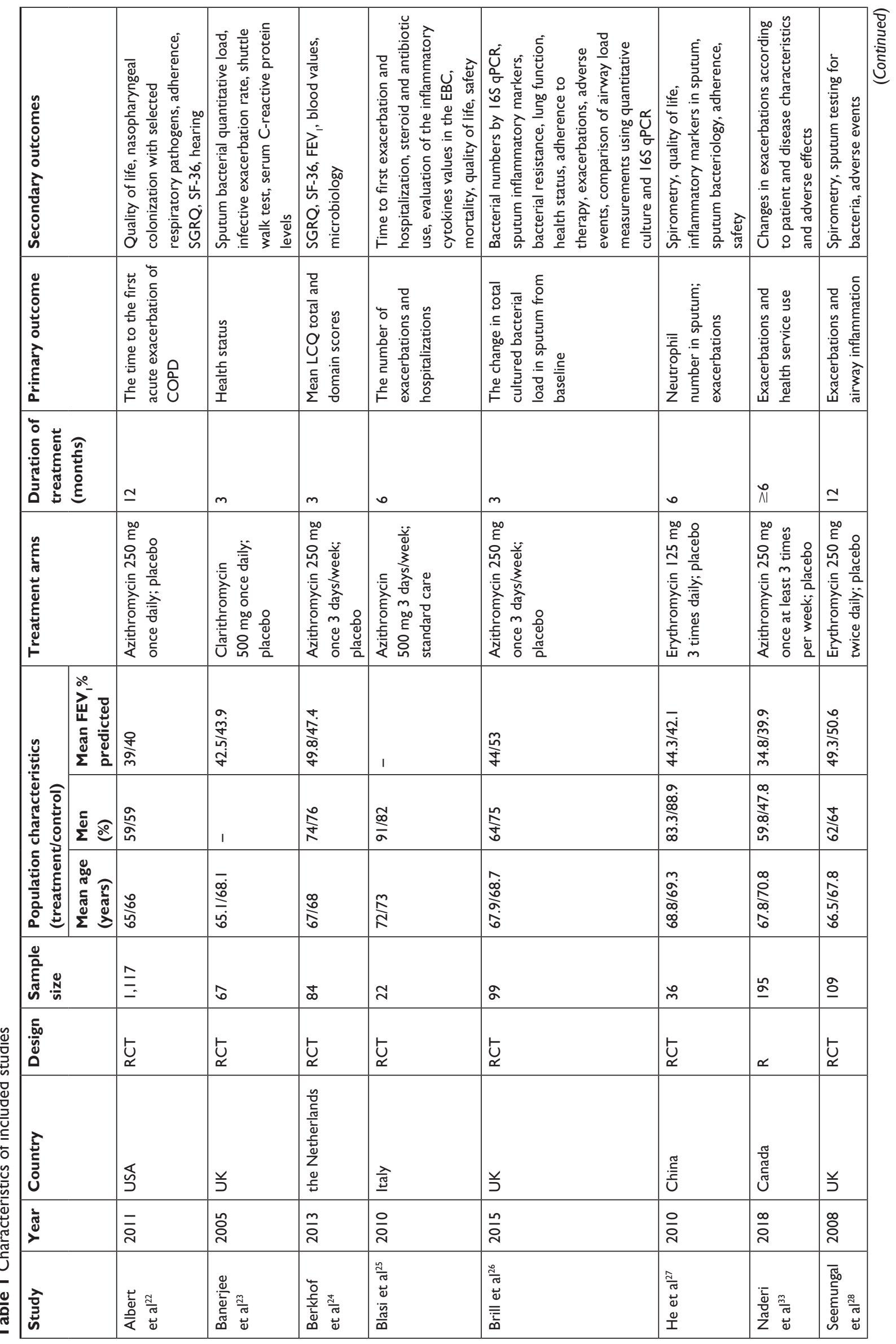




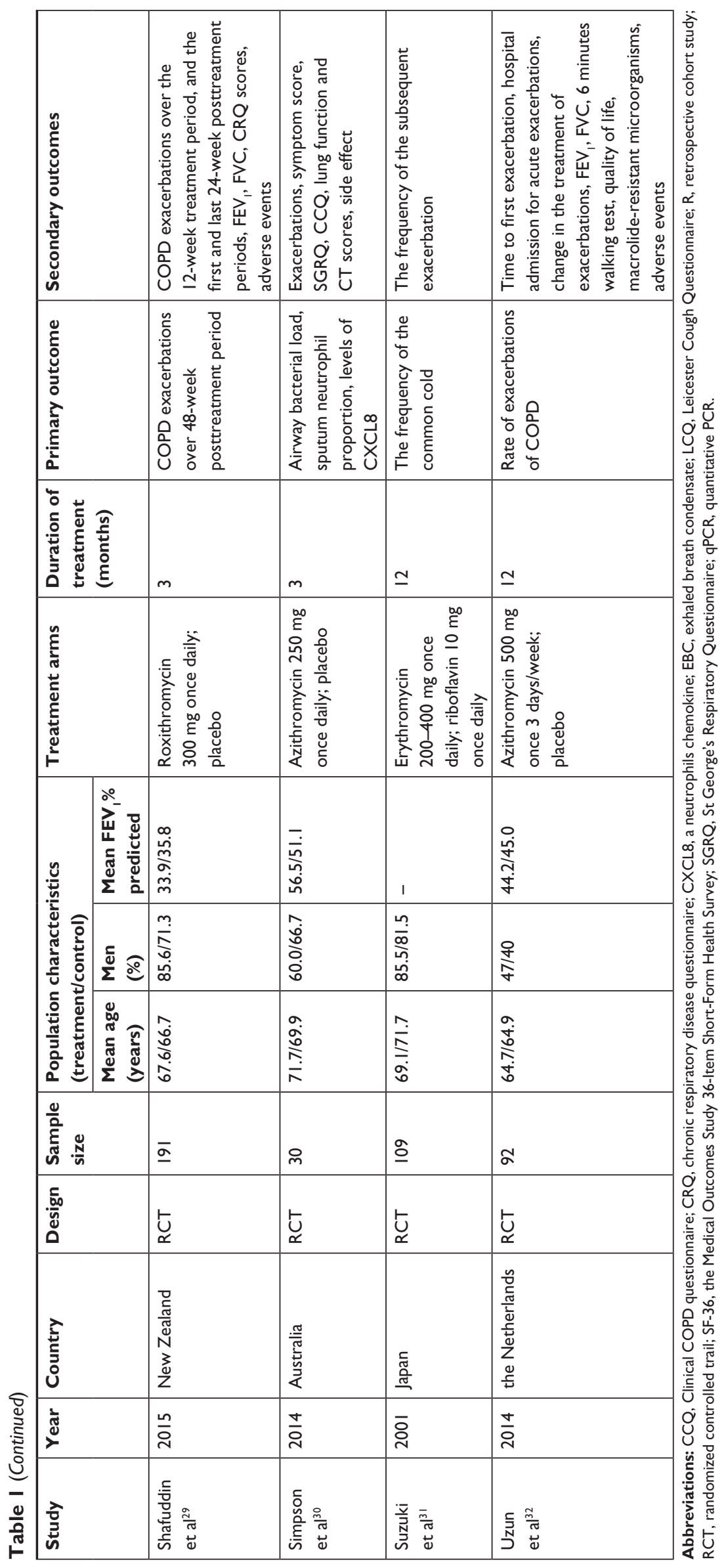



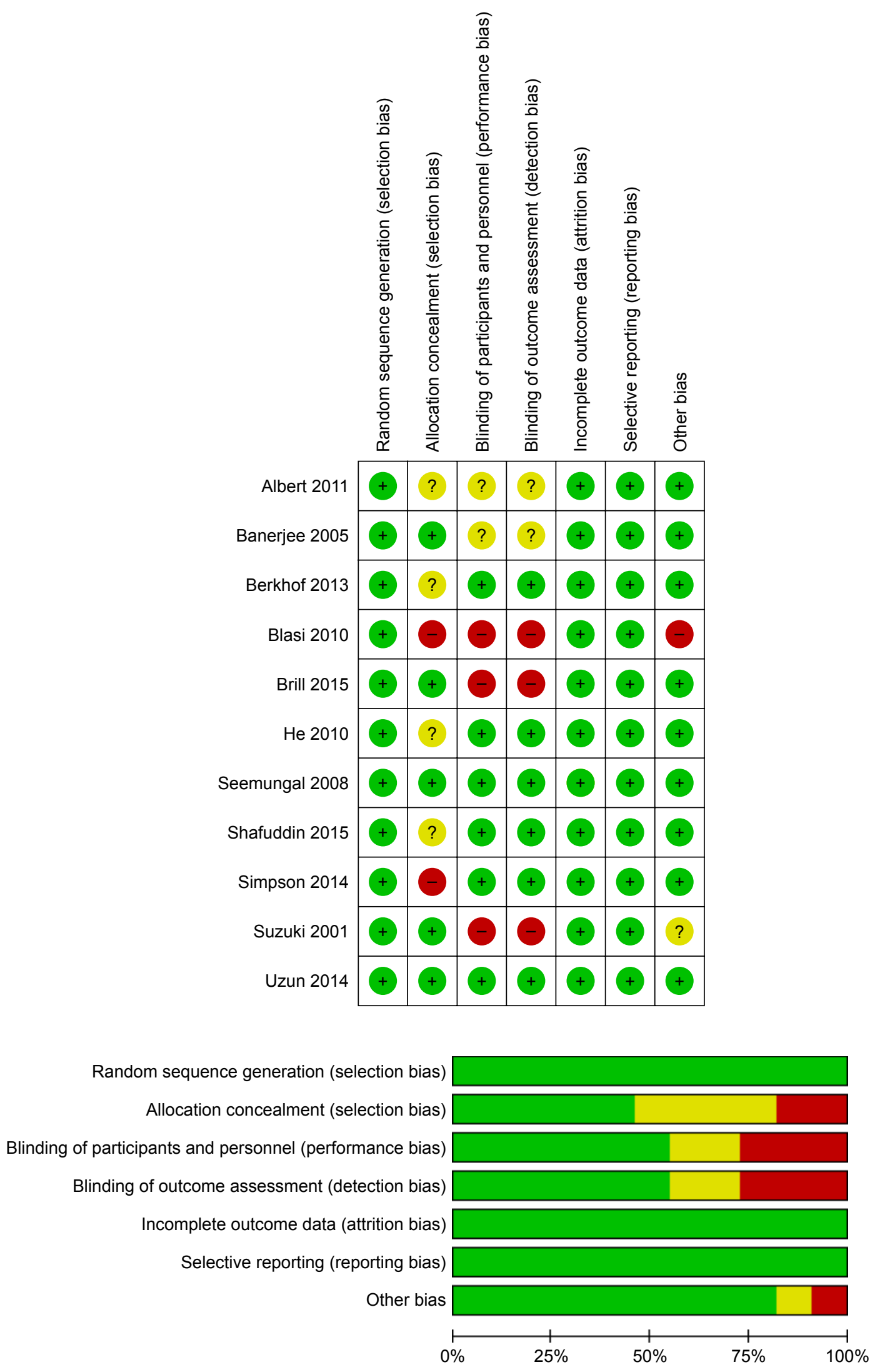

Low risk of bias $\square$ Unclear risk of bias $\square$ High risk of bias

Figure 2 Graph of the bias risk of the enrolled RCTs.

Note: The other bias refers to intention-to-treat analysis.

Abbreviation: RCT, randomized controlled trail. 
Table 2 Risk of bias in the retrospective study

\begin{tabular}{|c|c|c|c|c|c|c|c|c|}
\hline \multirow[t]{2}{*}{ Study } & \multicolumn{3}{|l|}{ Selection } & \multicolumn{2}{|c|}{ Comparability } & \multicolumn{2}{|l|}{ Outcome } & \multirow[t]{2}{*}{ Quality score } \\
\hline & $\begin{array}{l}\text { Representative } \\
\text { exposed group }\end{array}$ & $\begin{array}{l}\text { Representative } \\
\text { reference } \\
\text { group }\end{array}$ & $\begin{array}{l}\text { Assignment } \\
\text { for exposed } \\
\text { group }^{\mathrm{a}}\end{array}$ & $\begin{array}{l}\text { Comparable } \\
\text { for } 1,2,3,4^{b}\end{array}$ & $\begin{array}{l}\text { Comparable } \\
\text { for } 5,6,7,8^{b}\end{array}$ & $\begin{array}{l}\text { Assessment } \\
\text { of outcome }\end{array}$ & $\begin{array}{l}\text { Adequate } \\
\text { follow-up }\end{array}$ & \\
\hline $\begin{array}{l}\text { Naderi } \\
\text { et a }{ }^{33}\end{array}$ & Yes & Yes & Yes & 2,4 & 6,7 & Yes & Yes & 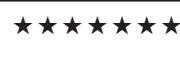 \\
\hline
\end{tabular}

Notes: Comparability variables: I=age; $2=$ gender; $3=\mathrm{FEV}$ (\%) of predicted; $4=$ corticosteroids inhalation medication; $5=$ body mass index; $6=$ smoking status; $7=$ any inhalation

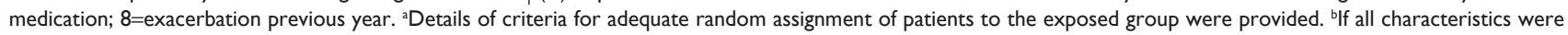
comparable, two stars; if two or three characteristics were comparable, one star; otherwise, no star.

three related studies, we retained two studie ${ }^{25,27}$ with similar weight and excluded the retrospective study. ${ }^{33}$ There was no change in the significance of any of the outcomes except for the number of patients with exacerbations using macrolide treatment for 6 months and the adverse events of azithromycin treatment (Figures S1-S5 and Table S1). In contrast with our previous results, macrolide treatment for 6 months could also reduce the number of AECOPDs $(P=0.02)$, and drug-related adverse events showed no significant differences between the azithromycin-treated group and control group ( $P=0.36$; Table S1). The degree of between-study heterogeneity decreased slightly for exacerbations, hospitalizations, and the RRs for exacerbations per patient per year but not for SGRQ total score or drug-related adverse effects.

Figure 10 shows a funnel plot of the studies included in this meta-analysis that reported the total number of patients with one or more exacerbations. All studies showed an even distribution around the vertical axis, indicating no obvious publication bias.

\section{Discussion}

Finding a way to effectively control chronic inflammation in COPD may be a key in reducing the number of AECOPDs.
Macrolides have drawn particular attention to their various functions including antimicrobial effects, anti-inflammatory effects, immune-modulating activity, and inhibitory effects on mucus secretion. ${ }^{34}$ The GOLD 2017 report also first proposed the use of azithromycin $(250 \mathrm{mg} /$ day or $500 \mathrm{mg}$ three times per week) or erythromycin (500 mg two times per day) for 1 year in patients prone to exacerbations. ${ }^{6}$ Many studies have reported the use of macrolides for the prevention of AECOPDs. However, the most suitable drug, drug dose, duration of therapy, and long-term efficacy and safety remain unclear. We believe that our study has contributed valuable information in this area, which is highly needed.

This meta-analysis of 11 RCTs and one retrospective observational study including 2,151 patients comparing the efficacy and safety of long-term prophylactic macrolide treatment and controls showed that macrolide treatment significantly reduced the risk of exacerbations and improved the total SGRQ score in patients with COPD. However, we found no significant differences in AECOPD-related hospitalizations. Moreover, there was a tendency toward greater drug-related adverse effects. Although macrolide treatment for AECOPD prevention has been reported by previous meta-analyses, we sought to provide such analysis on overall large sample of patients.

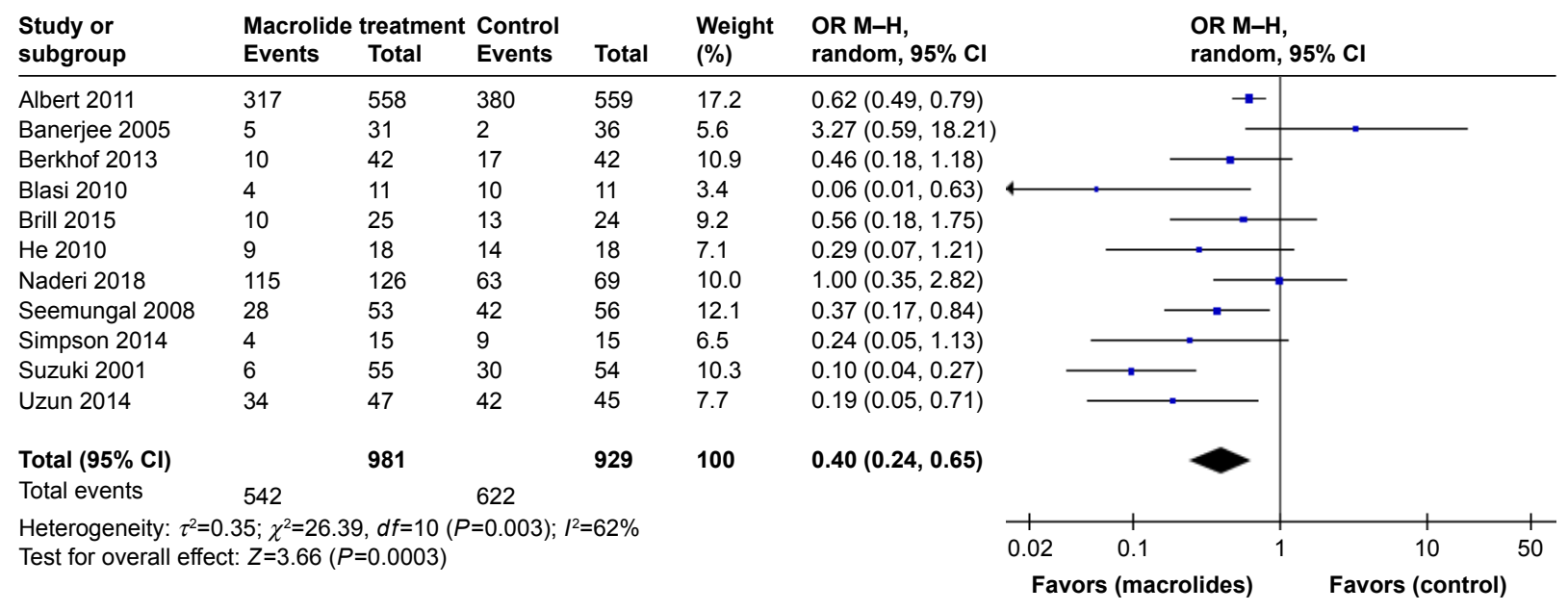

Figure 3 Forest plot and meta-analysis of the total number of patients with one or more exacerbations treated with macrolides compared with the control. Abbreviation: $\mathrm{M}-\mathrm{H}$, Mantel-Haenszel method. 


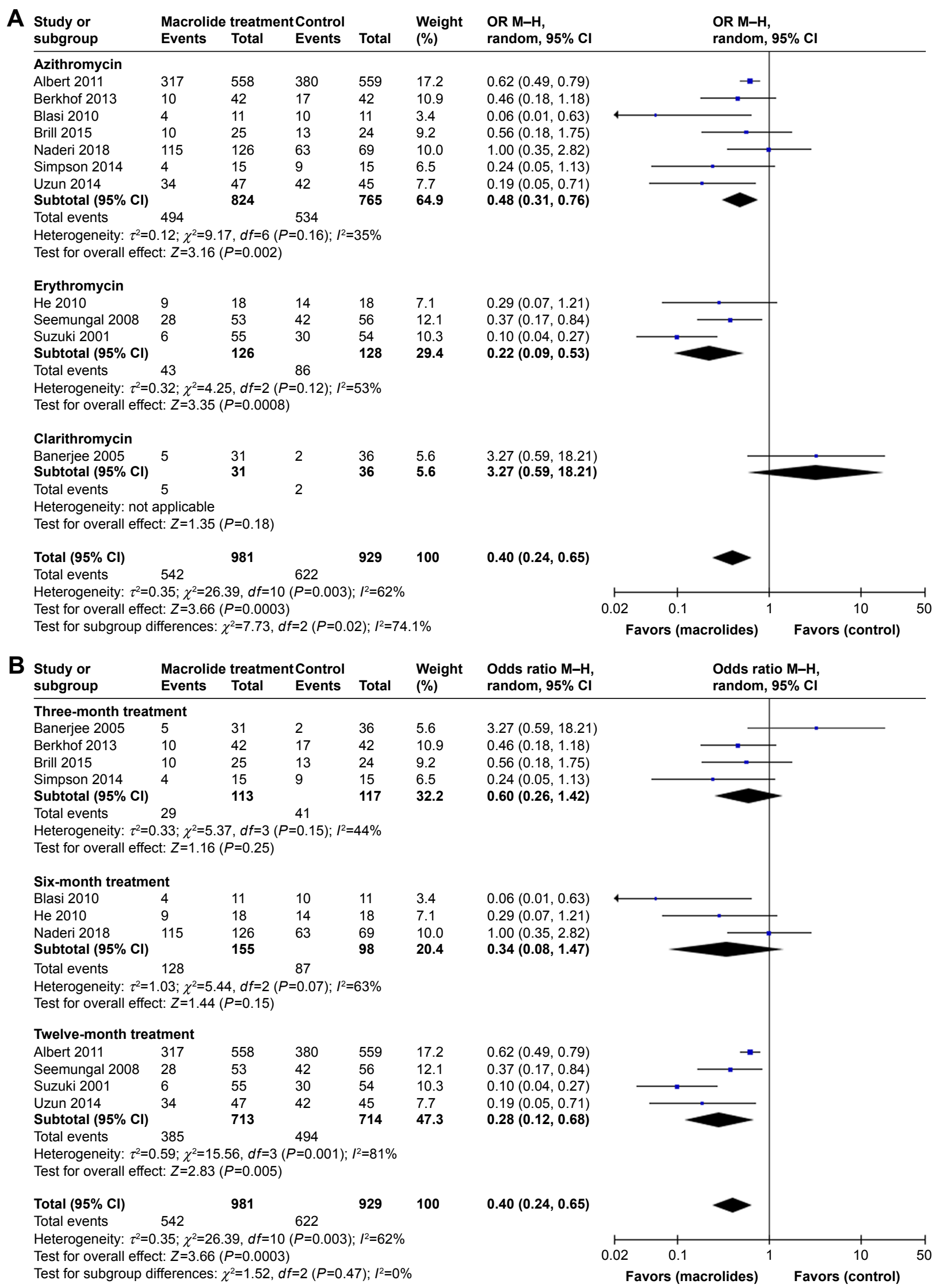

Figure 4 Forest plot and subgroup analyses of the total number of patients with one or more exacerbations treated with macrolides compared with the control: (A) different types of macrolides and (B) different durations of treatment.

Abbreviation: $\mathrm{M}-\mathrm{H}$, Mantel-Haenszel method. 


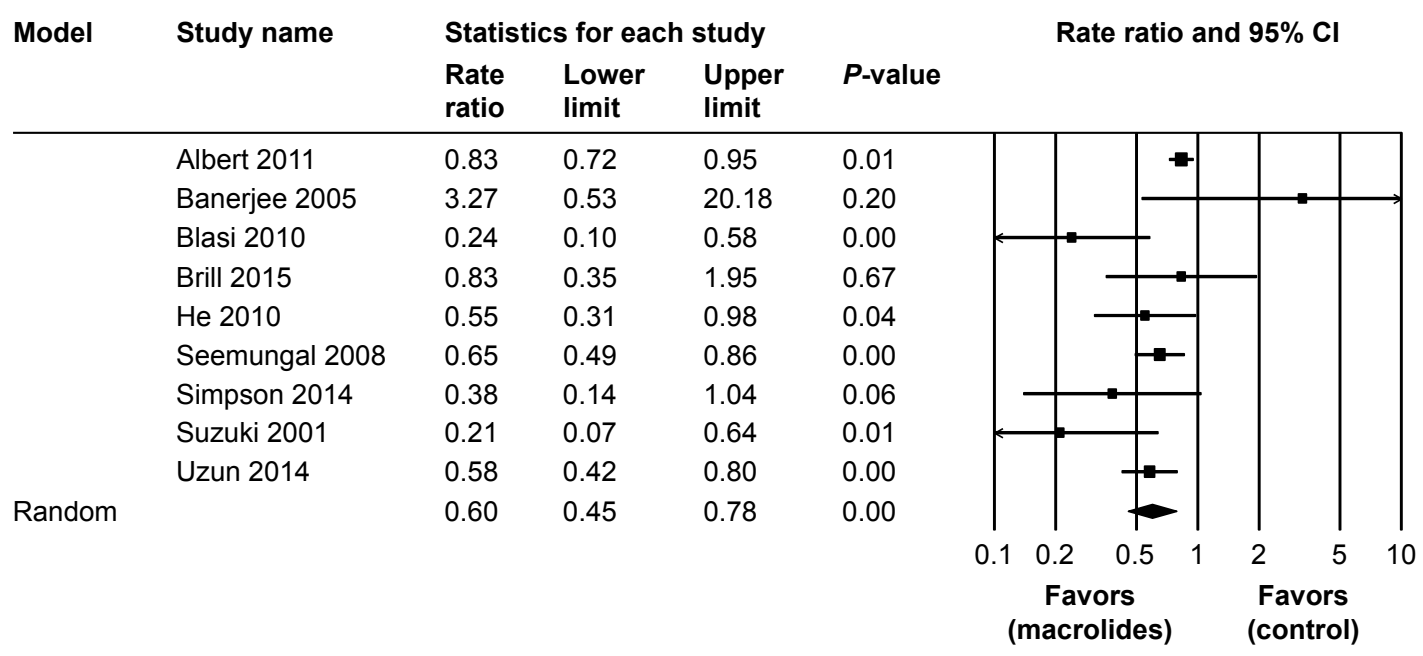

Figure 5 Forest plot and meta-analysis of risk ratios for exacerbations per patient per year treated with macrolides compared with the control.

The most common macrolides prescribed in the clinic are erythromycin, clarithromycin, and roxithromycin as 14-membered ring antibiotics and azithromycin as a 15-member compound. Recently, Huckle et a ${ }^{35}$ concluded that the use of continuous low-dose azithromycin or erythromycin therapy was supported to improve exacerbation-related COPD outcomes, but the evidence is incomplete regarding clarithromycin and roxithromycin. In our subgroup analyses, both azithromycin and erythromycin therapy could reduce the occurrence of AECOPDs, in keeping with a previous meta-analysis. ${ }^{14}$ Banerjee et $\mathrm{al}^{23}$ observed no differences in clinical outcomes between the clarithromycin and placebo groups. However, this may be because of the low dose and short duration of clarithromycin treatment. There were no available data on the number of patients with exacerbations and the rate ratio of the exacerbation rate related to roxithromycin therapy. ${ }^{29}$

The suitable duration of macrolide treatment has not been determined. A significant improvement in the prognosis of diffuse panbronchiolitis has reportedly been attributed to the use of long-term therapy with macrolide for no less than 6 months, the effect of which is also because of antiinflammatory and immunoregulatory effects. ${ }^{36}$ Our study including more patients indicated that only long-term macrolide treatment for at least 12 months reduced exacerbations. Nevertheless, treatment for 6 months was also effective in the sensitivity analyses upon excluding the study by Naderi et al. ${ }^{33}$ The authors recruited patients who were prescribed azithromycin for a minimum of 6 months, ${ }^{33}$ and the various durations of therapy may influence the results of our analysis. This indicated a relatively long-term macrolide therapy for at least 6 months to be suitable for prevention of exacerbations in COPD patients. Moreover, Naderi et a ${ }^{33}$ performed their study with a follow-up period of $32 \pm 22($ mean \pm SD) months in the azithromycin group and showed for the first time that the benefits of long-term azithromycin treatment persist beyond 1 year.

Regarding hospitalizations and the health-related quality of life, which are key variables in patients with COPD, there is no accordant conclusion among studies. In our meta-analysis, macrolide treatment did not reduce the rate of hospitalizations. It has been widely accepted that the

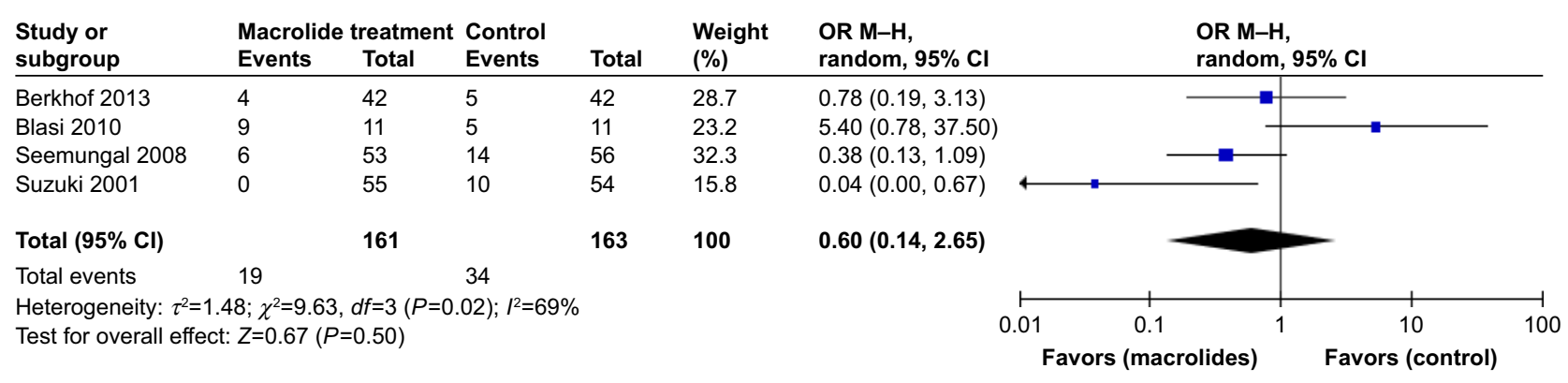

Figure 6 Forest plot and meta-analysis of the total number of patients requiring hospitalization treated with macrolides compared with the control. Abbreviation: M-H, Mantel-Haenszel method. 


\begin{tabular}{|c|c|c|c|c|c|c|c|c|c|c|}
\hline \multirow[t]{2}{*}{ Model } & \multirow[t]{2}{*}{ Study name } & \multicolumn{4}{|c|}{ Statistics for each study } & \multicolumn{5}{|c|}{ Difference in means and $95 \% \mathrm{Cl}$} \\
\hline & & $\begin{array}{l}\text { Difference } \\
\text { in means }\end{array}$ & $\begin{array}{l}\text { Lower } \\
\text { limit }\end{array}$ & $\begin{array}{l}\text { Upper } \\
\text { limit }\end{array}$ & $P$-value & & & & & \\
\hline & Albert 2011 & -2.20 & -3.58 & -0.82 & 0.00 & & & $\rightarrow$ & & \\
\hline & Berkhof 2013 & -7.50 & -12.43 & -2.57 & 0.00 & & & & & \\
\hline & Brill 2015 & -2.29 & -8.28 & 3.70 & 0.45 & & & & & \\
\hline & Simpson 2014 & -5.40 & -20.36 & 9.56 & 0.48 & & & & & \\
\hline & Uzun 2014 & -0.61 & -5.68 & 4.46 & 0.81 & & & & & \\
\hline \multirow[t]{3}{*}{ Fixed } & & -2.47 & -3.72 & -1.22 & 0.00 & & & - & & \\
\hline & & & & & & -20.00 & -10.00 & 0.00 & 10.00 & 20. \\
\hline & & & & & & & $\begin{array}{l}\text { Favors } \\
\text { acrolide }\end{array}$ & & $\begin{array}{l}\text { Favors } \\
\text { (control) }\end{array}$ & \\
\hline
\end{tabular}

Figure 7 Forest plot and meta-analysis of the mean differences in change in total SGRQ score among patients treated with macrolides compared with the control. Abbreviation: SGRQ, St George Respiratory Questionnaire.

minimum clinically important difference (MCID) in the SGRQ score was -4 units. ${ }^{37}$ Although our study showed an improvement of SGRQ in the treatment group, this change did not exceed the MCID of at least 4 units. Researchers have proposed that the greatest differences between frequent and infrequent exacerbators in the SGRQ are in the symptoms scale. ${ }^{38}$ Furthermore, Uzun et $\mathrm{al}^{32}$ reported that although azithromycin did not improve SGRQ, it had a clinically and statistically significant average treatment effect in the symptom component score of SGRQ. The improvement of SGRQ in our analysis might be attributable to the reduction in exacerbations.

There were still some other relevant aspects of treatment with macrolides, which we did not analyze due to the limited reported data. The positioning of macrolides in addition to usual care should be considered. As recommended by most guidelines, long-acting bronchodilators or ICS are commonly used to treat stable COPD. Some studies reported that macrolide treatment could reduce the exacerbation frequency and overcome any effect of ICS. ${ }^{28,32}$ Another crucial issue is to identify patients who benefit most from macrolide therapy. A post hoc analysis showed that greater efficacy was seen in older patients and milder GOLD stages, while treatment was less beneficial in active smokers. ${ }^{39}$ In New England Journal of Medicine, Wenzel et $\mathrm{al}^{40}$ suggested that long-term azithromycin prophylaxis should be considered in patients with a history of COPD with $\geq 2$ acute exacerbations in the previous year. In addition, the appropriate treatment regimen remains unknown, although studies involving patients with cystic fibrosis and bronchiectasis recommended an intermittent regimen of three times per week, and it was reported that daily dosing might lead to more side effects of azithromycin. ${ }^{41}$ Further studies are still required to address these inconsistencies among results.

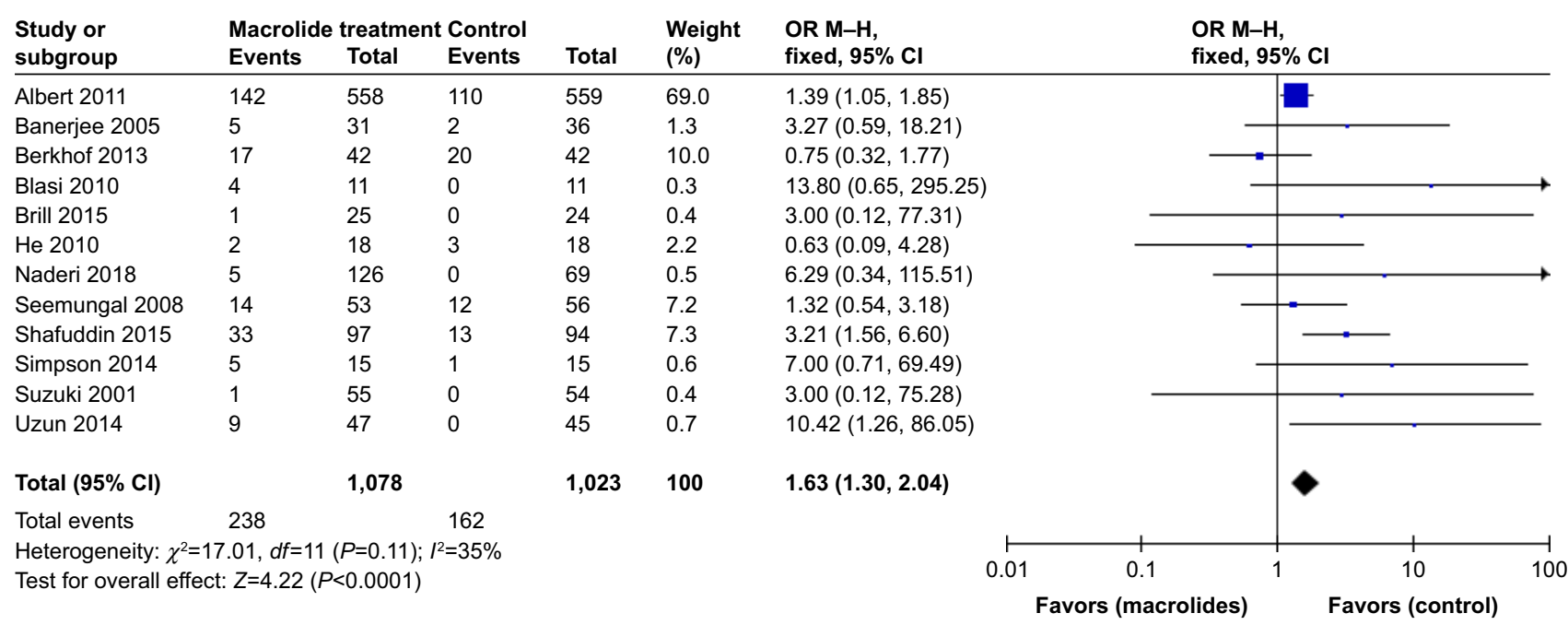

Figure 8 Forest plot and meta-analysis of the total number of patients who experienced adverse events during follow-up after treatment with macrolides compared with the control.

Abbreviation: $\mathrm{M}-\mathrm{H}$, Mantel-Haenszel method. 
It has been recognized that long-term macrolide treatment is related to various adverse effects. In our study, azithromycin therapy was more likely to be associated with side effects, but the sensitivity analyses showed no significant difference. The heterogeneity of the excluded study by Albert et $\mathrm{al}^{22}$ with a disproportionate number of patients and hearing impairment as its main outcome measures may explain the absence of a significant difference in the sensitivity analyses. As for nonfatal drug-related adverse events caused by erythromycin, clarithromycin, and roxithromycin treatment, the power of the subgroup analyses might be restricted because of the limited study number and population size. In addition, macrolide treatment for 3 or 12 months increased the risk of adverse effects, but not treatment for 6 months. These may be attributed to early individual intolerance with 3 months of treatment and the effect of cumulative drug and antibiotic resistance with 12 months of treatment. The sensitivity analyses further confirmed the accuracy and validity of the results.

The common adverse effects include gastrointestinal reactions, impairment of liver function, and hearing impairment. ${ }^{22,32}$ Cardiovascular toxic effects including QT interval prolongation are potentially important adverse events that should be considered. An observational retrospective study revealed an increased risk of cardiovascular death within 5 days of azithromycin therapy compared with amoxicillin or ciprofloxacin therapy. ${ }^{42}$ Another large retrospective cohort study found a small but significant increase in the odds of myocardial infarction observed in patients receiving azithromycin therapy. ${ }^{43}$ As a result, it is recommended to monitor QT interval, aminotransferase levels, and hearing impairment. ${ }^{40}$ Furthermore, antimicrobial resistance is a great concern in community populations. ${ }^{44}$ Albert et $\mathrm{al}^{22}$ reported that patients receiving azithromycin are less likely to become colonized

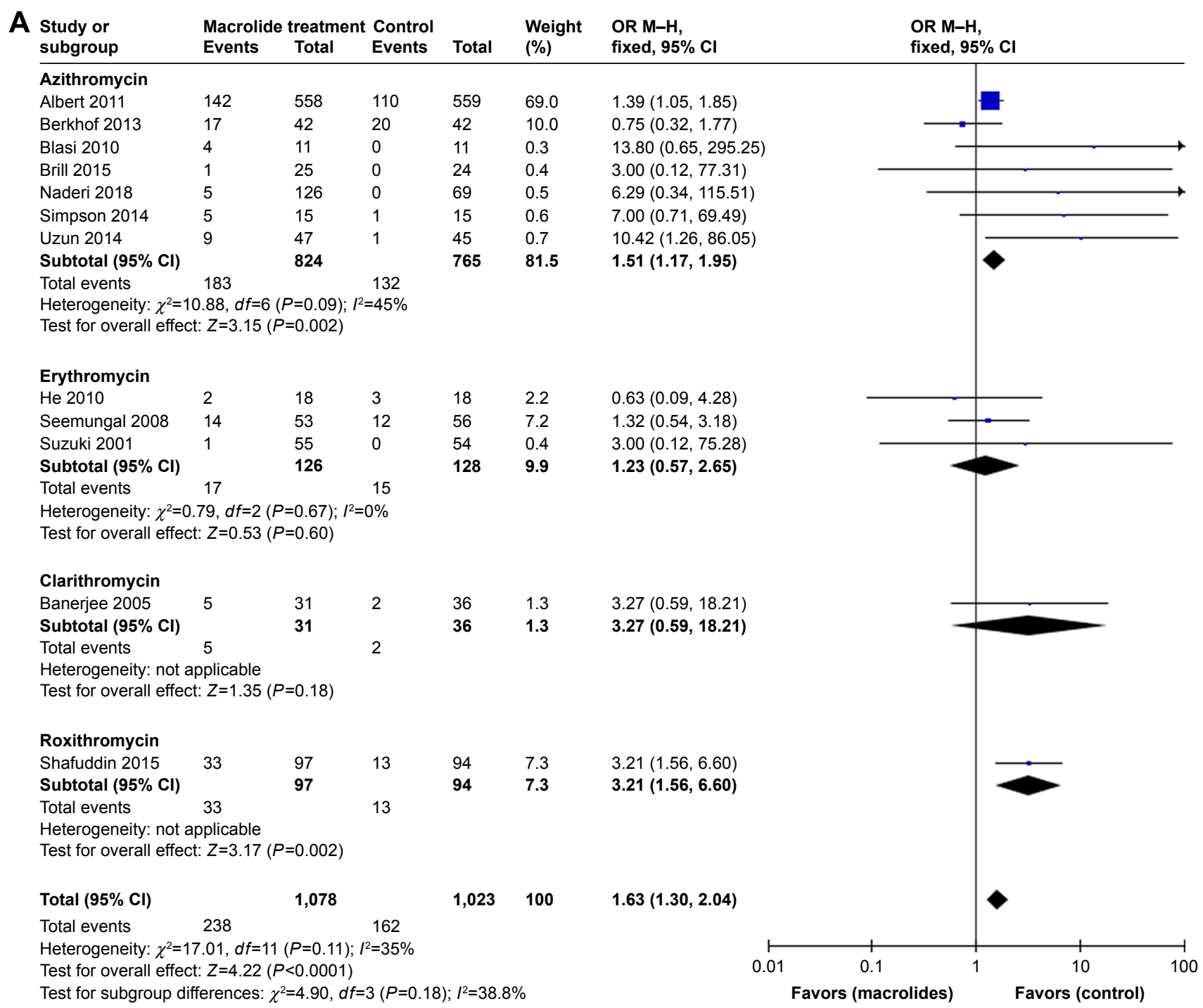

Figure 9 (Continued) 


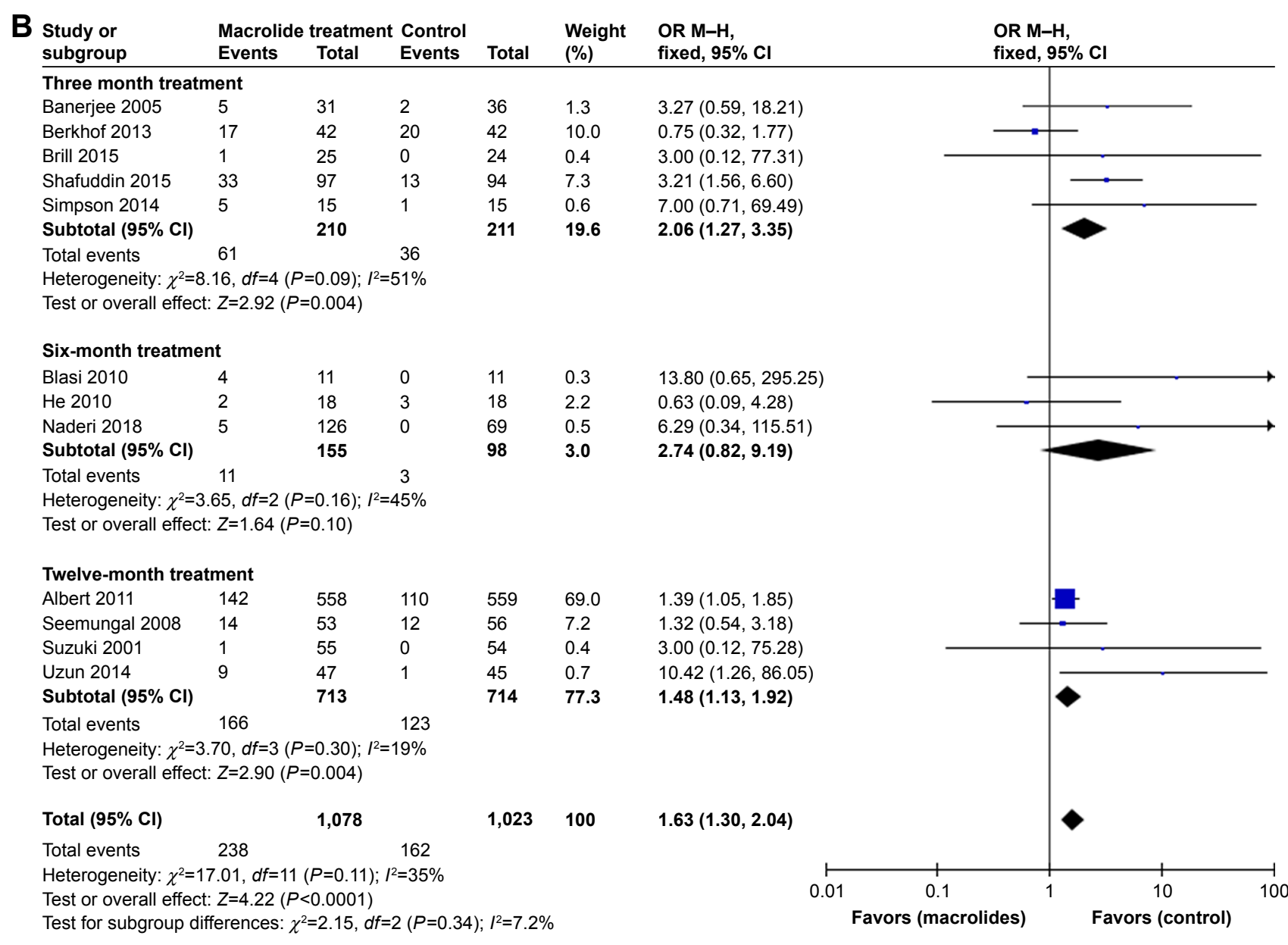

Figure 9 Forest plot and subgroup analyses of the total number of patients who experienced adverse events during follow-up after treatment with macrolides compared with the control: (A) different types of macrolides and (B) different durations of treatment.

Abbreviation: $\mathrm{M}-\mathrm{H}$, Mantel-Haenszel method.

with respiratory pathogens but are twice as likely to become colonized with macrolide-resistant organisms than control individuals. To overcome the potential effect of antimicrobial resistance of traditional long-term macrolide therapy, some

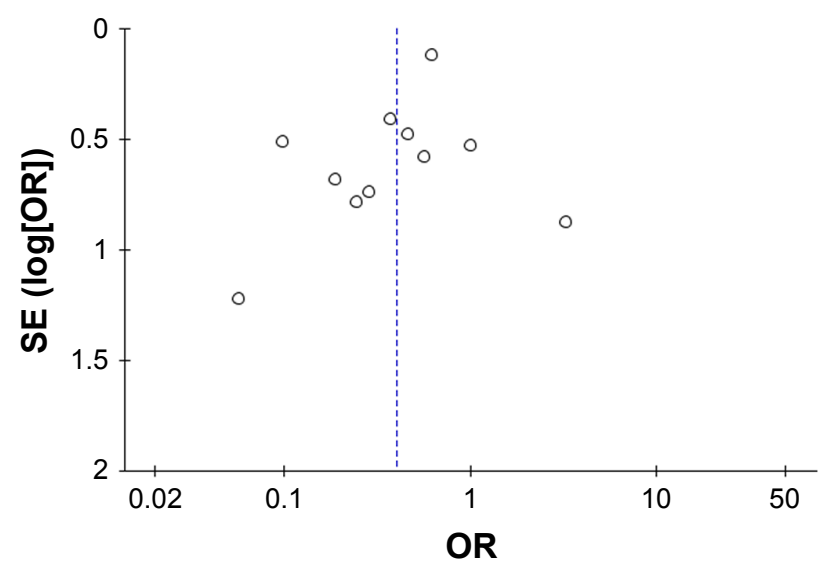

Figure 10 Funnel plots illustrating meta-analysis of the total number of patients with one or more exacerbations after treatment with macrolides compared with the control.

Abbreviation: SE, standard error. novel macrolides, with anti-inflammatory and immunomodulating effects but without antibiotic effects, have the potential to become the drugs of choice. ${ }^{45,46}$

The present meta-analysis has some limitations. First, some of the included studies were published several years ago, and there was only one retrospective observational study included. However, this meta-analysis was conducted at an appropriate time, because the GOLD 2017 report recommended the long-term macrolide treatment for the prevention of AECOPDs for the first time and the treatment duration and drug-related adverse events remain controversial. It is important to urgently accumulate more relevant evidence. Besides, the retrospective study included in our meta-analysis was valuable, because it was the only one that was newly published in 2018 with a follow-up period of more than 1 year. Hence, we provide the most up-to-date information in this area. Second, there were limited data providing the rates and dichotomous and continuous variables needed in our meta-analysis. We then used both Review Manager 5.3 and Comprehensive Meta-Analysis V2.2 to conduct the analysis. 
Third, the included studies had different inclusion criteria, types of macrolides, and treatment durations. We applied subgroup and sensitivity analyses to minimize the heterogeneity. Fourth, the drug dosage, treatment regimen, and concomitant drugs $( \pm \mathrm{ICS})$ were not considered in the statistical analyses; this may have reduced the reliability of our results. Fifth, the limited number of studies and sample size for certain subgroup analyses restricts the power of our analysis. Sixth, there were no data showing the efficacy or safety of chronic azithromycin treatment beyond 1 year except the retrospective study. Finally, the side effects of long-term macrolide therapy were varied and changed over time. We did not perform further analysis on the specific adverse events.

\section{Conclusion}

Prophylactic azithromycin or erythromycin treatment has a significant effect in reducing the frequency of AECOPD in a time-dependent manner. However, long-term macrolide treatment could increase the occurrence of adverse events and macrolide resistance. We suggest that macrolides should be carefully used as maintenance therapy in COPD patients with frequent exacerbations in the previous year despite optimal therapy. Future large-scale, well-designed RCTs with extensive follow-up would be required to confirm and update the findings of this analysis.

\section{Acknowledgment}

This study was supported by the National Science Foundation of China (No 81400032, No 81600031, and No 81873410) and the National Key Clinical Specialty Construction Projects of China.

\section{Author contributions}

Yanan Cui, Yan Chen, and Ping Chen conceived and designed the experiments. Yanan Cui, Lijuan Luo, and Chenbei Li were responsible for acquisition of data. Yanan Cui analyzed the data and wrote the paper. All authors contributed to data analysis, drafting or revising the article, gave final approval of the version to be published, and agree to be accountable for all aspects of the work.

\section{Disclosure}

The authors report no conflicts of interest in this work.

\section{References}

1. GOLD Executive Committee [homepage on the Internet]. Global strategy for the diagnosis management and prevention of chronic obstructive pulmonary disease; 2018. Available from: http://goldcopd.com. Accessed October 25, 2018.
2. Adeloye D, Chua S, Lee C, et al. Global and regional estimates of COPD prevalence: Systematic review and meta-analysis. J Glob Health. 2015;5(2):020415.

3. Wang C, Xu J, Yang L, et al. Prevalence and risk factors of chronic obstructive pulmonary disease in China (the China Pulmonary Health [CPH] study): a national cross-sectional study. Lancet. 2018;391(10131): $1706-1717$.

4. Vestbo J, Edwards LD, Scanlon PD, et al. Changes in forced expiratory volume in 1 second over time in COPD. N Engl J Med. 2011;365(13): 1184-1192.

5. Barnes PJ. Inhaled corticosteroids in COPD: a controversy. Respiration. 2010;80(2):89-95.

6. GOLD Executive Committee [homepage on the Internet]. Global strategy for the diagnosis management and prevention of chronic obstructive pulmonary disease.; 2017. Available from: http://goldcopd.com. Accessed October 25, 2018.

7. Sadarangani SP, Estes LL, Steckelberg JM. Non-anti-infective effects of antimicrobials and their clinical applications: a review. Mayo Clin Proc. 2015;90(1):109-127.

8. Altenburg J, de Graaff CS, van der Werf TS, Boersma WG. Immunomodulatory effects of macrolide antibiotics - part 1: biological mechanisms. Respiration. 2011;81(1):67-74.

9. Kudoh S, Azuma A, Yamamoto M, Izumi T, Ando M. Improvement of survival in patients with diffuse panbronchiolitis treated with lowdose erythromycin. Am J Respir Crit Care Med. 1998;157(6 Pt 1): 1829-1832.

10. Florescu DF, Murphy PJ, Kalil AC. Effects of prolonged use of azithromycin in patients with cystic fibrosis: a meta-analysis. Pulm Pharmacol Ther. 2009;22(6):467-472.

11. Figueiredo Bde C, Ibiapina Cda C. The role of macrolides in noncystic fibrosis bronchiectasis. Pulm Med. 2011;2011:751982.

12. Kuse N, Abe S, Hayashi H, et al. Long-term efficacy of macrolide treatment in idiopathic pulmonary fibrosis: a retrospective analysis. Sarcoidosis Vasc Diffuse Lung Dis. 2016;33(3):242-246.

13. Zhang HL, Tan M, Qiu AM, Tao Z, Wang CH. Antibiotics for treatment of acute exacerbation of chronic obstructive pulmonary disease: a network meta-analysis. BMC Pulm Med. 2017;17(1):196.

14. Ni W, Shao X, Cai X, et al. Prophylactic use of macrolide antibiotics for the prevention of chronic obstructive pulmonary disease exacerbation: a meta-analysis. PLoS One. 2015;10(3):e0121257.

15. Donath E, Chaudhry A, Hernandez-Aya LF, Lit L. A meta-analysis on the prophylactic use of macrolide antibiotics for the prevention of disease exacerbations in patients with Chronic Obstructive Pulmonary Disease. Respir Med. 2013;107(9):1385-1392.

16. Lee JS, Park DA, Hong Y, et al. Systematic review and meta-analysis of prophylactic antibiotics in COPD and/or chronic bronchitis. Int J Tuberc Lung Dis. 2013;17(2):153-162.

17. Yao GY, Ma YL, Zhang MQ, Gao ZC. Macrolide therapy decreases chronic obstructive pulmonary disease exacerbation: a meta-analysis. Respiration. 2013;86(3):254-260.

18. Djamin RS, Uzun S, Kluytmans JAJW, et al. Macrolides for Reducing Acute Exacerbations of Chronic Obstructive Pulmonary Disease. Clin Pulm Med. 2016;23(1):16-22.

19. Albert RK, Schuller JL, COPD Clinical Research Network. Macrolide antibiotics and the risk of cardiac arrhythmias. Am J Respir Crit Care Med. 2014;189(10):1173-1180.

20. Higgins JP, Altman DG, Gøtzsche PC, et al. The Cochrane Collaboration's tool for assessing risk of bias in randomised trials. $B M J$. 2011;343:d5928.

21. Wells G, Shea B, O'Connell D [webpage on the Internet]. The NewcastleOttawa Scale (NOS) for assessing the quality of nonrandomised studies inmeta-analyses; 2012. Available from: http://www.ohri.ca/programs/ clinical_epidemiology/oxford.asp. Accessed October 25, 2018.

22. Albert RK, Connett J, Bailey WC, et al. Azithromycin for Prevention of Exacerbations of COPD. N Engl J Med Overseas Ed. 2011;365(8): 689-698. 
23. Banerjee D, Khair OA, Honeybourne D. The effect of oral clarithromycin on health status and sputum bacteriology in stable COPD. Respir Med. 2005;99(2):208-215.

24. Berkhof FF, Doornewaard-Ten Hertog NE, Uil SM, Kerstjens HA, van den Berg JW. Azithromycin and cough-specific health status in patients with chronic obstructive pulmonary disease and chronic cough: a randomised controlled trial. Respir Res. 2013;14(1):125.

25. Blasi F, Bonardi D, Aliberti S, et al. Long-term azithromycin use in patients with chronic obstructive pulmonary disease and tracheostomy. Pulm Pharmacol Ther. 2010;23(3):200-207.

26. Brill SE, Law M, El-Emir E, et al. Effects of different antibiotic classes on airway bacteria in stable COPD using culture and molecular techniques: a randomised controlled trial. Thorax. 2015;70(10):930-938.

27. He ZY, Ou LM, Zhang JQ, et al. Effect of 6 months of erythromycin treatment on inflammatory cells in induced sputum and exacerbations in chronic obstructive pulmonary disease. Respiration. 2010;80(6):445-452.

28. Seemungal TA, Wilkinson TM, Hurst JR, Perera WR, Sapsford RJ, Wedzicha JA. Long-term erythromycin therapy is associated with decreased chronic obstructive pulmonary disease exacerbations. Am J Respir Crit Care Med. 2008;178(11):1139-1147.

29. Shafuddin E, Mills GD, Holmes MD, Poole PJ, Mullins PR, Black PN A double-blind, randomised, placebo-controlled study of roxithromycin and doxycycline combination, roxithromycin alone, or matching placebo for 12 weeks in adults with frequent exacerbations of chronic obstructive pulmonary disease. J Negat Results Biomed. 2015;14(1):15.

30. Simpson JL, Powell H, Baines KJ, et al. The effect of azithromycin in adults with stable neutrophilic COPD: a double blind randomised, placebo controlled trial. PLoS One. 2014;9(8):e105609.

31. Suzuki T, Yanai M, Yamaya M, et al. Erythromycin and common cold in COPD. Chest. 2001;120(3):730-733.

32. Uzun S, Djamin RS, Kluytmans JA, et al. Azithromycin maintenance treatment in patients with frequent exacerbations of chronic obstructive pulmonary disease (COLUMBUS): a randomised, double-blind, placebo-controlled trial. Lancet Respir Med. 2014;2(5):361-368.

33. Naderi N, Assayag D, Mostafavi-Pour-Manshadi SM, et al. Long-term azithromycin therapy to reduce acute exacerbations in patients with severe chronic obstructive pulmonary disease. Respir Med. 2018;138: 129-136
34. Araki N, Yanagihara K, Morinaga Y, et al. Azithromycin inhibits nontypeable Haemophilus influenzae-induced MUC5AC expression and secretion via inhibition of activator protein-1 in human airway epithelial cells. Eur J Pharmacol. 2010;644(1-3):209-214.

35. Huckle AW, Fairclough LC, Todd I. Prophylactic antibiotic use in COPD and the potential anti-inflammatory activities of antibiotics. Respir Care. 2018;63(5):609-619.

36. Poletti V, Casoni G, Chilosi M, Zompatori M. Diffuse panbronchiolitis. Eur Respir J. 2006;28(4):862-871.

37. Jones PW. St. George's Respiratory Questionnaire: MCID. COPD. 2005 2(1):75-79.

38. Miravitlles M, Ferrer M, Pont A, et al. Effect of exacerbations on quality of life in patients with chronic obstructive pulmonary disease: a 2 year follow up study. Thorax. 2004;59(5):387-395.

39. Han MK, Tayob N, Murray S, et al. Predictors of chronic obstructive pulmonary disease exacerbation reduction in response to daily azithromycin therapy. Am J Respir Crit Care Med. 2014;189(12):1503-1508.

40. Wenzel RP, Fowler AA 3rd, Edmond MB. Antibiotic prevention of acute exacerbations of COPD. $N$ Engl J Med. 2012;367(4):340-347.

41. Saiman L, Anstead M, Mayer-Hamblett N, et al. Effect of azithromycin on pulmonary function in patients with cystic fibrosis uninfected with Pseudomonas aeruginosa: a randomized controlled trial. JAMA. 2010; 303(17):1707-1715.

42. Ray WA, Murray KT, Hall K, Arbogast PG, Stein CM. Azithromycin and the Risk of Cardiovascular Death. NEngl J Med Overseas Ed. 2012; 366(20):1881-1890.

43. Mortensen EM, Halm EA, Pugh MJ, et al. Association of azithromycin with mortality and cardiovascular events among older patients hospitalized with pneumonia. JAMA. 2014;311(21):2199-2208.

44. Serisier DJ, Martin ML, McGuckin MA, et al. Effect of long-term, lowdose erythromycin on pulmonary exacerbations among patients with non-cystic fibrosis bronchiectasis: the BLESS randomized controlled trial. JAMA. 2013;309(12):1260-1267.

45. Balloy V, Deveaux A, Lebeaux D, et al. Azithromycin analogue CSY0073 attenuates lung inflammation induced by LPS challenge. Br J Pharmacol. 2014;171(7):1783-1794.

46. Sugawara A, Shima H, Sueki A, et al. Non-antibiotic 12-membered macrolides: design, synthesis and biological evaluation in a cigarettesmoking model. J Antibiot. 2016;69(4):319-326. 


\section{Supplementary materials}

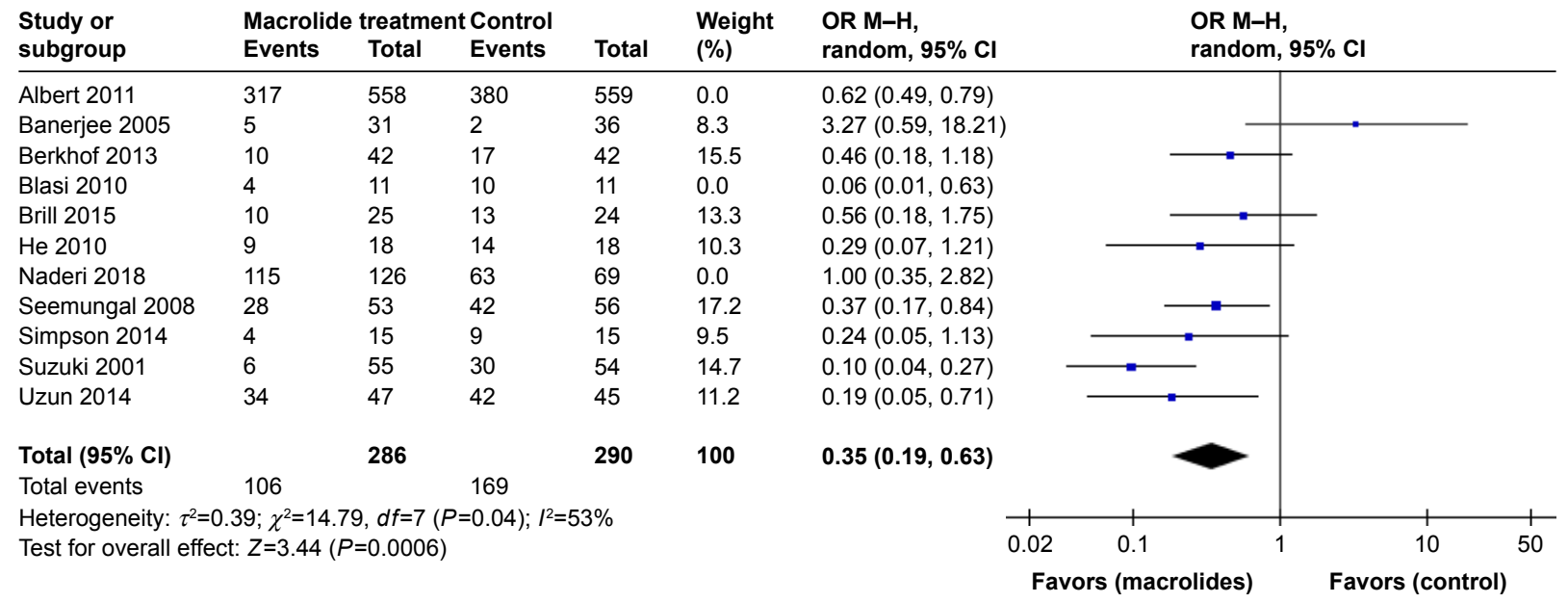

Figure SI Sensitivity analyses of the total number of patients with one or more exacerbations treated with macrolides compared with the control. Abbreviation: M-H, Mantel-Haenszel method.

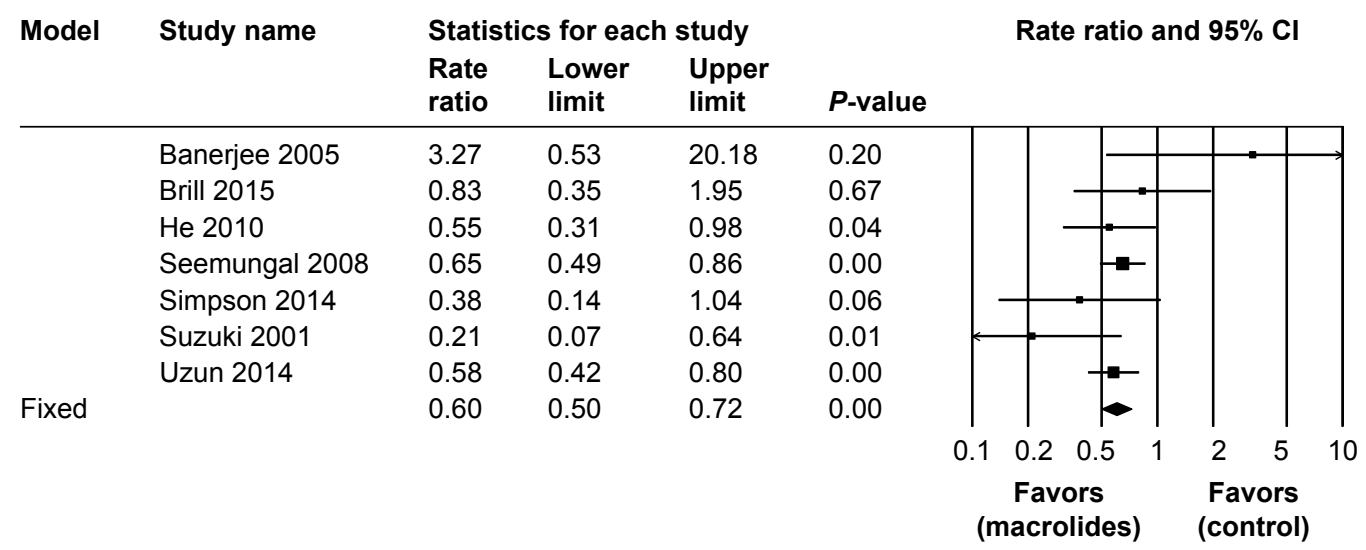

Figure S2 Sensitivity analyses of risk ratios for exacerbations per patient per year treated with macrolides compared with the control.

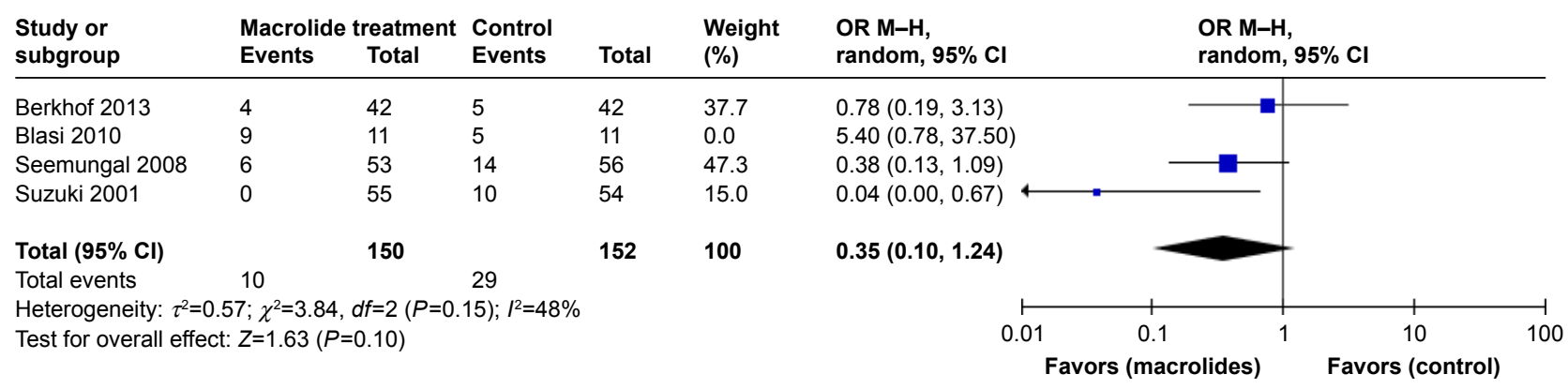

Figure S3 Sensitivity analyses of the total number of patients requiring hospitalization treated with macrolides compared with the control. Abbreviation: M-H, Mantel-Haenszel method. 


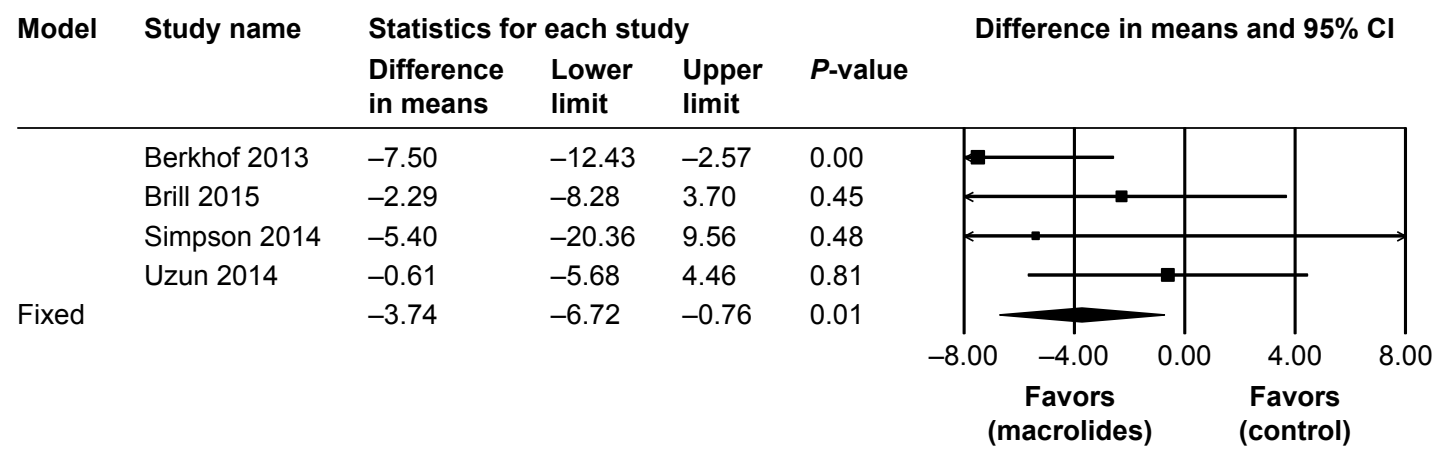

Figure S4 Sensitivity analyses of the mean differences with respect to change in total SGRQ score among patients treated with macrolides compared with the control. Abbreviation: SGRQ, St George Respiratory Questionnaire.

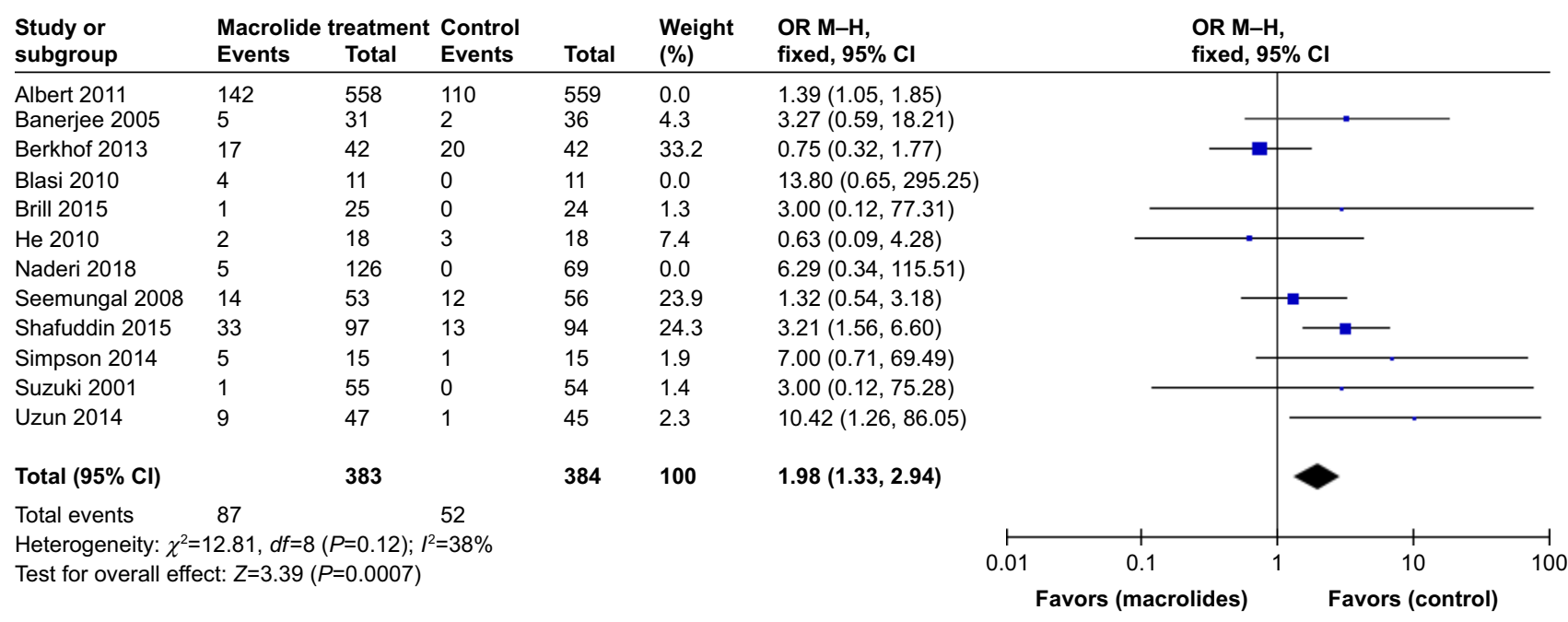

Figure S5 Sensitivity analyses of the total number of patients who experienced adverse events during follow-up after treatment with macrolides compared with the control. Abbreviation: $\mathrm{M}-\mathrm{H}$, Mantel-Haenszel method.

Table SI Sensitivity analyses of subgroup based on the number of patients with exacerbations and adverse effects

\begin{tabular}{|c|c|c|c|c|c|c|}
\hline & \multicolumn{3}{|c|}{ Number of patients with exacerbations } & \multicolumn{3}{|c|}{ Adverse effects } \\
\hline & Studies (n) & OR $(95 \% \mathrm{Cl})$ & $P$-value & Studies (n) & OR $(95 \% \mathrm{Cl})$ & $P$-value \\
\hline Azithromycin & 4 & $0.37(0.21-0.67)$ & 0.001 & 4 & $1.38(0.69-2.78)$ & 0.36 \\
\hline Erythromycin & 3 & $0.22(0.09-0.53)$ & 0.0008 & 3 & $1.23(0.57-2.65)$ & 0.6 \\
\hline Clarithromycin & 1 & $3.27(0.59-18.21)$ & 0.18 & 1 & $3.27(0.59-18.21)$ & 0.18 \\
\hline Roxithromycin & 0 & NA & NA & 1 & $3.21(1.56-6.60)$ & 0.002 \\
\hline Three-month treatment & 4 & $0.60(0.26-1.42)$ & 0.25 & 5 & $2.06(1.27-3.35)$ & 0.004 \\
\hline Six-month treatment & 2 & $0.17(0.04-0.75)$ & 0.02 & 2 & $2.0 \mathrm{I}(0.5 \mathrm{I}-7.86)$ & 0.32 \\
\hline Twelve-month treatment & 3 & $0.20(0.08-0.47)$ & 0.0002 & 3 & $2.16(1.03-4.53)$ & 0.04 \\
\hline
\end{tabular}

Abbreviation: NA, data not available.

International Journal of COPD

\section{Publish your work in this journal}

The International Journal of COPD is an international, peer-reviewed journal of therapeutics and pharmacology focusing on concise rapid reporting of clinical studies and reviews in COPD. Special focus is given to the pathophysiological processes underlying the disease, intervention programs, patient focused education, and self management protocols.

\section{Dovepress}

This journal is indexed on PubMed Central, MedLine and CAS. The manuscript management system is completely online and includes a very quick and fair peer-review system, which is all easy to use. Visit http://www.dovepress.com/testimonials.php to read real quotes from published authors. 